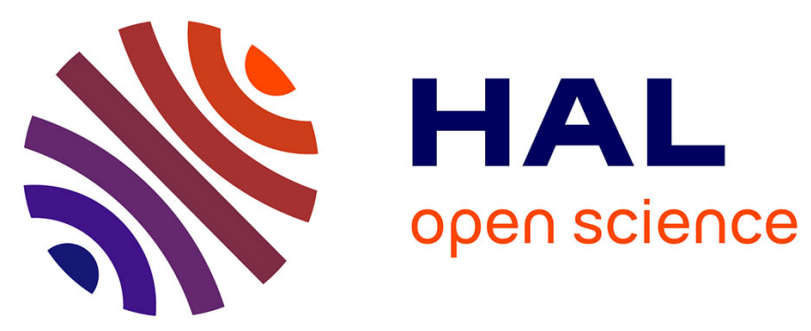

\title{
Functionalization of cyclic olefin copolymer substrates with polyethylene glycol diacrylate for the in situ synthesis of immobilized nanoparticles
}

Josiane Saade, Nina Declas, Pedro Marote, Claire Bordes, Karine Faure

\section{- To cite this version:}

Josiane Saade, Nina Declas, Pedro Marote, Claire Bordes, Karine Faure. Functionalization of cyclic olefin copolymer substrates with polyethylene glycol diacrylate for the in situ synthesis of immobilized nanoparticles. Journal of Materials Science, 2017, 52 (8), pp.4509-4520. 10.1007/s10853-016-0696-8 . hal-01515322

\author{
HAL Id: hal-01515322 \\ https://hal.science/hal-01515322
}

Submitted on 23 Jul 2020

HAL is a multi-disciplinary open access archive for the deposit and dissemination of scientific research documents, whether they are published or not. The documents may come from teaching and research institutions in France or abroad, or from public or private research centers.
L'archive ouverte pluridisciplinaire HAL, est destinée au dépôt et à la diffusion de documents scientifiques de niveau recherche, publiés ou non, émanant des établissements d'enseignement et de recherche français ou étrangers, des laboratoires publics ou privés. 


\title{
Functionalization of cyclic olefin copolymer substrates with polyethylene glycol diacrylate for the in situ synthesis of immobilized nanoparticles
}

\author{
Josiane Saadé, Nina Declas, Pedro Marote, Claire Bordes, and Karine Faure \\ Université de Lyon, CNRS, Université Claude Bernard Lyon 1, ENS de Lyon, Institut des \\ Sciences Analytiques, UMR 5280, 5 rue de la Doua, F-69100 VILLEURBANNE, France \\ karine.faure@isa-lyon.fr
}

\section{$\begin{array}{lll}1 & 1 & \text { Introduction }\end{array}$}

2 Microfluidic systems are actually in development owing to their significant advantages: the 3 reduction of solvent consumption and the faster analysis. Furthermore, the implementation of 4 nanoparticles as novel stationary phase in microchips could in the future offer enhanced 5 chromatographic performances as shown by Knox and other authors [1-4]. Up to now, the smallest 6 particles in conventional columns present $1.7 \mu \mathrm{m}$ as diameter [5].

7 Usually, polymers colloids are made from emulsion polymerization, like miniemulsion, which 8 could be thermally [6] or photochemically initiated [7, 8]. UV irradiation approach allows 9 polymerization in enclosed system in few minutes and at room temperature without stirring. 10 Thereby, the synthesis of hexyl acrylate nanoparticles $\left(\mathrm{C}_{6}\right)$ was executed by emulsion radical 11 polymerization. Miniemulsion composition was previously optimized by central composite design 12 and $\mathrm{C}_{6}$ nanoparticles, obtained after photopolymerization was monodisperse with a diameter 13 inferior to $200 \mathrm{~nm}$ which could be used as new stationary phase [9]. To anchor nanoparticles into 14 microchips, the polymerization of miniemulsion is initiated in-situ by the abstraction of hydrogen 15 from the surface.

16 Photoinitiator type II like benzophenone (BP), react by hydrogen abstraction from the surface and 17 form ketyl (semipicanol) free radical and an alkyl free radical [10-14]. Benzoin methyl ether 18 (BME) is a type I photoinitiator used in polymerization to generate free radicals and as it has been 19 showed by Ladner et al.[15], it can react with COC by abstracting hydrogen from the surface. This 
process, allows the photografting of acrylate nanoparticles on COC surface under UV irradiation

21 at $365 \mathrm{~nm}$. Wang et al. [16, 17] reported the photografting of methyl methacrylate/ 1,2divinylbenzene (MMA/DVB) emulsion, initiated by UV-irradiation on polypropylene (PP) film. Nanoparticles diameter is about $30 \mathrm{~nm}$ and $60 \mathrm{~nm}$, anchored by covalent bond on PP film, using 24 benzophenone as photoinitiator. Furthermore, the formation of group dormant permits a growth of the multilayer graft nanoparticles. The anchorage of nanoparticles into microchips depends on the nature of the material. A variety material have been used, for different applications, such silicon : polydimethylsiloxane (PDMS), glass, quartz, thermoplastic materials like poly (methylmethacrylate) (PMMA) and polyolefin such as polyethylene (PE), polypropylene (PP) and cyclic olefin copolymer (COC). $\mathrm{COC}$ is one of the most widely used because of its resistance to many organic solvents, its transparency below

$31300 \mathrm{~nm}[18,19]$ and optical detection.

Preliminary synthesis of spherical $\mathrm{C}_{6}$ nanoparticles on $\mathrm{COC}$ chips revealed the need of surface modification. Hydrophobic nature of the material seems disturbing miniemulsion stability during in-situ photopolymerization. To promote the approach and the anchorage of spherical nanoparticles to the surface, many methodologies of $\mathrm{COC}$ surface modification are proposed using physical or chemical coating [20]. In literature, Roy et al. [21, 22] discussed the physical COC coating by plasma treatment using argon and argon-oxygen to enhance hydrophilicity and increase wettability of $\mathrm{COC}$ surface. Both treatments showed an increase of wettability and roughness, but compared to argon plasma, oxygenated-plasma increased more effectively the wettability of COC surface. Other approaches including UV/ozone oxidation treatment [23], dynamic coating with hydrophilic polymers [24], covalent grafting method by aryldiazonium salts [25] and UVphotografting of hydrophilic polymers $[26,27]$ are used for COC microchannels modification.

UV-photografting of hydrophilic polymers is a common strategy for modification of polydimethylsiloxane (PDMS) [28-30] and thermoplastic materials [20,31] : polyethylene films [13, 32-35], polypropylene substrates [16, 17, 36-40], polycarbonateurethane [41] and cyclic olefin copolymer (COC) [15, 26, 42-47]. UV-photografting of COC surface allows modification to

47 hydrophilic surface without changing bulk properties, such as optical properties. One of the advantages is the covalent grafted chains offers stable surfaces in contrast to the physical coating which can be delaminated [45]. Modification of COC surface was discussed for different 
applications, cited in literature like fabrication of smart disposable LOCs for the BIOMEMS

51 applications [45], the bioanalytical applications that require minimal nonspecific adsorption of

52 biomolecules [27], and to increase bond strength of the original surface [43]. However, very few

53 examples are to be found. Li et al. [26] studied the UV-photografting of a hydrophilic

54 polyacrylamide on COC devices in order to reduce protein adsorption and make COC suitable for

55 proteins separations by isoelectric focusing gel electrophoresis. In this example, polyacrylamide

56 grafting was initiated in presence of benzophenone (BP) as photoinitiator. The surface

57 hydrophilicity was characterized by contact angle measurements. Hydrophilicity increased with

58 coating time and for $20 \mathrm{~min}$ of UV-irradiation, contact angle measured is $12^{\circ}-16^{\circ}$. PA-coating

59 modified COC surfaces to hydrophilic properties and kept low electroosmotic mobilities. In

60 another example, Du et al. [46] improved the hydrophilicity of COC devices by photografting six

61 acrylates with anionic, neutral and cationic functional groups, to obtain different surface charges.

62 Benzophenone was used as photoinitiator. Influence of irradiation conditions: monomer

63 concentration, reaction temperature, irradiation intensity and time, was followed by contact angle

64 measurements. On COC microchannels modified with 2- acrylamido - 2- methyl -1- propane

65 sulfonic (AMPS) and N-[3-(dimethyl-amino)propyl] methacrylamide, an electrophoretic

66 separation of fluorescein isothiocyanate labeled amino acids was reported. A zwitterionic

67 molecules were successfully grafted by Peng et al. [47] onto the surface of COC microfluidic

68 channels by UV-irradiation of mixed acrylic monomers : 2- acrylamido - 2- methyl -1- propane

69 sulfonic (AMPS) and [2-(acryloyloxy)ethyl]trimethyl ammonium chloride (AETAC). Contact

70 angle showed a modification of COC surface, with BP as photoiniator, with low angle obtained

71 for ratio AETAC/AMPS = 5.5. These modified COC microchannels showed a highly efficient

72 separation of amino acid, indicating that the surface modification led to a uniform zwitterionic

73 layer.

74 The focus of this work is the surface modification of COC plates, by UV photografting of the 75 hydrophilic monomer: polyethylene glycol diacrylate (PEGDA). For this purpose, an optimisation 76 of PEGDA photografting was investigated by using a central composite design (CCD) in order to 77 obtain a hydrophilic COC surface which enhances anchoring of hexyl acrylate nanoparticle $\left(\mathrm{C}_{6}\right)$.

78 Surface morphology was observed by scanning electronic microscopy (SEM) to follow the 79 influence of hydrophilic surface on particles sphericity. 


\section{Experimental section}

81

82

83

\subsection{Materials}

All chemicals were supplied by Sigma-Aldrich (Isle - d'Abeau, France) and used as received: sodium dodecyl sulfate (SDS) as surfactant, hexyl acrylate (HA), 2- acrylamide - 2- methyl propane sulfonic acid (AMPS), polyethylene glycol diacrylate (PEGDA 258) as monomers, benzoin methyl ether (BME) as photoinitiator, and pentadecane $\left(\mathrm{C}_{15}\right)$ as co-stabilizer. Solvents used were acetone and water of Milli-Q grade (resistivity: $18 \mathrm{M} \Omega$ ).

Cyclic olefin copolymer plates (COC, Topas 6013) in format $75.5 \mathrm{~mm}$ x $25.5 \mathrm{~mm}$, thickness $1.0 \mathrm{~mm}$, were fabricated by Microfluidic Chipchop GmbH (Jena, Germany). These plates were rinsed with acetone and dried under nitrogen before use.

\subsection{Hydrophilic monomer PEGDA photografting on COC surface}

Hydrophilic monomer PEGDA were mixed to BME and solubilized in acetone under agitation and ultrasound. Aqueous solutions containing different concentrations of PEGDA and BME were tested. BME amount is expressed as weight pourcentage (wt. \%) in respect with PEGDA weight or as concentration in water $(\mathrm{mol} / \mathrm{L})$. A volume of approximately $500 \mu \mathrm{L}$ PEGDA-BME mixture was deposed on native COC plate, then enclosed with another COC plate without causing bubbles which could disturbs the polymerization.

\subsection{Miniemulsion formulation and polymerisation}

Surfactant sodium dodecyl sulfate (SDS) and charged monomer 2- acrylamido - 2- methyl -1propane sulfonic acid (AMPS) were dissolved in water forming the aqueous phase $\left(\varphi_{\mathrm{aq}}\right)$. The organic phase ( $\left.\varphi_{\text {org }}\right)$ was prepared with the monomer hexyl acrylate (HA), the photoinitiator benzoin methyl ether (BME) and the co-stabilizer pentadecane $\left(\mathrm{C}_{15}\right)$. The composition of the miniemulsion was fixed at $0.1 \mathrm{wt}$. \% SDS and $0.025 \mathrm{wt}$ \% AMPS in the aqueous phase mixed to the organic phase constituted of 5 wt. $\%$ HA, 0.35 wt. $\% \mathrm{C}_{15}$ and 0.125 wt. \% BME. All amounts are expressed in weight percentage (wt. \%) with respect to the water weight. 
105 Both phases were then mixed in a beaker during 10 min using a magnetic stirrer at $700 \mathrm{rpm}$ leading 106 to an oil-in-water pre-emulsion. This dispersion was then mini-emulsified by ultrasonication with 107 a sonifier (W450 DigitalBranson) at 50\% amplitude for $180 \mathrm{~s}$.

108 Miniemulsion was injected between two PEGDA-modified COC plates, and miniemulsion 109 polymerization is performed under irradiation intensity of $2.7 \mathrm{~mW} / \mathrm{cm}^{2}$ for $30 \mathrm{~min}$ at $30{ }^{\circ} \mathrm{C}$. After 110 polymerization, plates are rinsed with deionized water to eliminate non reacted reagents and 111 solvents.

\section{$112 \quad 2.4$ Characterization of COC surface}

\section{$113 \quad 2.4 .1 \quad$ Contact angle measurements}

114 A droplet of distilled water $(3.3 \mu \mathrm{L})$ was dropped off on COC surface at room temperature. The 115 contact angles measured by Digidrop Contact Meter (GBX,Bourg de Péage, France) instrument,

116 are the averages of 15 measurements performed at different locations of the surface.

\section{$117 \quad 2.4 .2 \quad$ Scanning electron microscopy}

118 Morphology of nanoparticles on PEGDA grafted-COC- surfaces were observed by scanning 119 electron microscopy (FEI Quanta FEG 250). Plates were covered with a thin layer (10 - $20 \mathrm{~nm}) \mathrm{of}$ 120 metal conductor (like platinum or gold-palladium) prior to SEM observations, in order to reduce 121 the charge phenomenon on non-conducting material.

\section{$122 \quad 2.5 \quad$ Optimization design}

123 Surface response methodology as applied to optimize PEGDA photografting in order to obtain a 124 hydrophilic COC surface. The experimental factors studied were the amount of PEGDA (X1), 125 BME (X2) and irradiation time (X3). Others factors were fixed: the solubilization mixture was 126 acetone/water $50 / 50(\mathrm{v} / \mathrm{v})$, temperature was fixed at $45^{\circ} \mathrm{C}$ and intensity of irradiation at $1272.7 \mathrm{~mW} / \mathrm{cm}^{2}$. The response $\mathrm{Y}$ was the contact angle measured on both plates.

128 A central composite design (CCD) was built with a second-order quadratic equation to model the 129 contact angle (Y1) as follows: 
$Y=b_{0}+b_{1} X_{1}+b_{2} X_{2}+b_{3} X_{3}+b_{12} X_{1} X_{2}+b_{13} X_{1} X_{3}+b_{23} X_{2} X_{3}+b_{11} X_{1}^{2}+b_{22} X_{2}^{2}+b_{33} X_{3}^{2}$

132 Where $\mathrm{Y}$ is the modeled response ( $\mathrm{Y} 1), \mathrm{b}_{0}$ is the intercept, $\mathrm{X}_{\mathrm{i}}$ is the coded factor, $\mathrm{b}_{\mathrm{i}}$ is the 133 corresponding coefficient, $b_{i i}$ is the quadratic coefficient and $b_{i j}$ is the two-factor interaction 134 coefficient.

13517 experiments were thus carried out determined by the $2^{3}$ full factorial design with six axial points 136 at a distance of $\alpha=1$ from the design center and three center points. The experimental factors and 137 their levels are given in Table 1.

138 Multiple linear regression, analysis of variance (ANOVA) and residual analysis were performed 139 with NemrodW ${ }^{\circledR}$ software (LPRAI, Marseille, France).

Table 1 Experimental factors and their coded levels in the central composite design, with the corresponding amounts of PEGDA (mol/L) and BME (wt. \% with respect to PEGDA weight) and irradiation time (min).

\begin{tabular}{|l|l|l|l|}
\hline Level & {$[\mathrm{PEGDA}](\mathrm{mol} / \mathrm{l})$} & BME (wt. \%) & Irradiation time (min) \\
\hline-1 & 0.1 & 1 & 10 \\
\hline 0 & 0.2 & 3 & 15 \\
\hline 1 & 0.3 & 5 & 20 \\
\hline
\end{tabular}

\section{Results and discussion}

145 Miniemulsion photopolymerization on native COC plates showed a need of surface modification.

146 Hydrophobic surface of COC seems disturbing miniemulsion stability and therefore, spherical

147 particles were not anchored. An acrylate layer was obtained. With the view to increasing the 148 surface coverage, UV-photografting of ionic and neutral monomers was investigated. Firstly, 149 hydrophobic monomer was tested: ethylene glycol dicyclopentenylether acrylate (DCP). It's a 150 monomer which has a norbornene group like $\mathrm{COC}$ surface, and could be a spacer to anchorage 151 nanoparticles. This grafting, showed an increase of active sites, but acrylate layers were formed. 152 Secondly, many hydrophilic monomers were investigated looking for a hydrophilic surface: 2153 acrylamido - 2- methyl -1- propane sulfonic acid (AMPS), 2 (methacryloyloxy) 
154 ethyltrimethylammonium chloride (MATEA) and polyethylene glycol diacrylate (PEGDA 258 155 and PEGDA 700). Only PEGDA (258) photografting, showed the anchorage of monodisperse 156 spherical particles. An optimization was studied by experimental design in order to obtain an 157 homogeneous grafting.

\section{$158 \quad 3.1 \quad$ Optimization of PEGDA photografting}

159 Experimental design was built to study the influence of PEGDA concentration, BME amount 160 expressed as percentage in regards to PEGDA weight and irradiation time on surface 161 hydrophilicity by contact angle measurements. PEGDA and BME amounts impact the number and 162 the crosslinking of PEG chains. Furthermore, irradiation time affects the density and the length of 163 PEG chains.

164 Table 2 shows 17 experiments in different conditions, with contact angle measurements as 165 response. Standard deviation, calculated for 15 points in different locations on COC plates, 166 indicates the surface homogeneity of PEGDA grafting. COC plate is considered hydrophilic when 167 contact angle reached a value below $65^{\circ}$. Amongst 17 experiments, only three conditions meet

168 these requirements: test 4,8 and 12 . Test 8 was irradiated for 20 min at the same amounts of 169 PEGDA and BME of test 4, and showed a contact angle slightly superior to the value obtained for 170 the test 4. For test 12, PEGDA grafting was not homogeneous and less reproducible. The low value 171 of contact angle with good homogeneity $(59 \pm 3)$ was obtained for experiment 4 for the following 172 conditions: $0.3 \mathrm{M}$ PEGDA, 5 wt. \% BME for 10 min of irradiation. The synthesis of nanoparticles 173 on photografted COC plates for these conditions was investigated. 
186 Table 2 Three-factor central composite design with corresponding response: contact angle measurements $187 \pm$ standard deviation. The amount of BME is express in weight percent with respect to PEGDA weight.

\begin{tabular}{|c|c|c|c|c|}
\hline Experiments & [PEGDA] (M) & wt. \% BME & $\begin{array}{l}\text { Irradiation } \\
\text { time (min) }\end{array}$ & $\begin{array}{l}\text { Contact angle }\left({ }^{\circ}\right) \\
\pm \text { standard deviation }\end{array}$ \\
\hline \multirow{2}{*}{1} & \multirow{2}{*}{0.10} & \multirow{2}{*}{1} & \multirow{2}{*}{10} & $83 \pm 3$ \\
\hline & & & & $85 \pm 1$ \\
\hline \multirow{2}{*}{2} & \multirow{2}{*}{0.30} & \multirow{2}{*}{1} & \multirow{2}{*}{10} & $71 \pm 6$ \\
\hline & & & & $70 \pm 6$ \\
\hline \multirow{2}{*}{3} & \multirow{2}{*}{0.10} & \multirow{2}{*}{5} & \multirow{2}{*}{10} & $78 \pm 4$ \\
\hline & & & & $76 \pm 4$ \\
\hline \multirow{2}{*}{4} & \multirow{2}{*}{0.30} & \multirow{2}{*}{5} & \multirow{2}{*}{10} & $59 \pm 3$ \\
\hline & & & & $59 \pm 3$ \\
\hline \multirow{2}{*}{5} & \multirow{2}{*}{0.10} & \multirow{2}{*}{1} & \multirow{2}{*}{20} & $84 \pm 6$ \\
\hline & & & & $84 \pm 7$ \\
\hline \multirow{2}{*}{6} & \multirow{2}{*}{0.30} & \multirow{2}{*}{1} & \multirow{2}{*}{20} & $69 \pm 5$ \\
\hline & & & & $72 \pm 5$ \\
\hline \multirow{2}{*}{7} & \multirow{2}{*}{0.10} & \multirow{2}{*}{5} & \multirow{2}{*}{20} & $74 \pm 9$ \\
\hline & & & & $73 \pm 5$ \\
\hline \multirow{2}{*}{8} & \multirow{2}{*}{0.30} & \multirow{2}{*}{5} & 20 & $65 \pm 4$ \\
\hline & & & 20 & $65 \pm 7$ \\
\hline & & & & $79 \pm 5$ \\
\hline 9 & 0.10 & 3 & 15 & $80 \pm 3$ \\
\hline & & & & $78 \pm 7$ \\
\hline 10 & 0.30 & 3 & 15 & $81 \pm 5$ \\
\hline & & & & $84 \pm 2$ \\
\hline 11 & 0.20 & 1 & 15 & $85 \pm 1$ \\
\hline & & & & $61 \pm 8$ \\
\hline 12 & 0.20 & 5 & 15 & $67 \pm 9$ \\
\hline 13 & 020 & 3 & 10 & $85 \pm 3$ \\
\hline 15 & 0.20 & 3 & 10 & $81 \pm 3$ \\
\hline & & & & $77 \pm 5$ \\
\hline 14 & 0.20 & 3 & 20 & $78 \pm 4$ \\
\hline 15 & 020 & 3 & 15 & $87 \pm 2$ \\
\hline 15 & 0.20 & 3 & 15 & $85 \pm 3$ \\
\hline
\end{tabular}




\begin{tabular}{|l|l|l|l|l|}
\hline 16 & 0.20 & 3 & 15 & $81 \pm 6$ \\
\hline 17 & 0.20 & 3 & 15 & $84 \pm 8$ \\
\cline { 4 - 5 } & & $37 \pm 6$ & $73 \pm 7$ \\
\hline
\end{tabular}

188

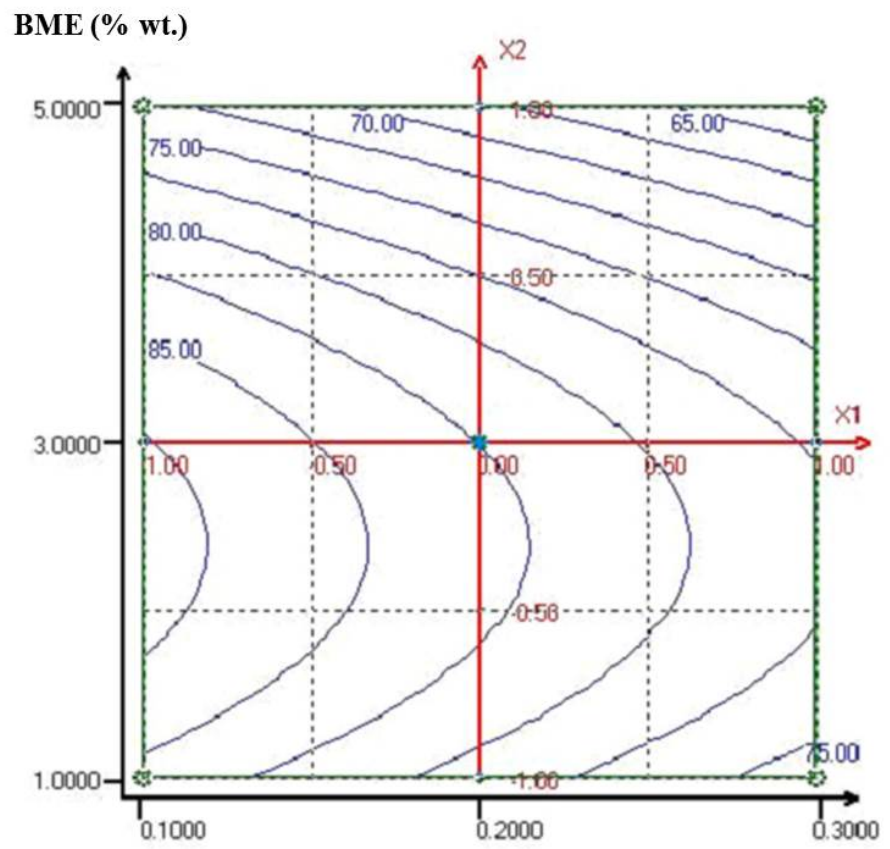

[PEGDA] (M)

190 Figure 1 : Contour plot of contact angle for $10 \mathrm{~min}$ of irradiation.

192 The results shown in Table 2 for 17 experiments done in different conditions were analyzed by a 193 contour plot. This plot (Figure 4) allows the determination of PEGDA and BME concentrations 194 leading to hydrophilic surface after photopolymerization during a specific irradiation time. 195 Contour plots for different irradiation time tested were similar, so irradiation time has no influence 196 on the response. Therefore, $10 \mathrm{~min}$ of irradiation was fixed. The plot also revealed a decrease of 197 contact angle values, so an increase of hydrophilicity for high amounts of PEGDA (0.3 M) and 198 BME (5 wt. \%).

\subsection{Increase of PEGDA concentration}

200 In order to enhance the hydrophilic character of COC plates, an increase of PEGDA concentration

201 might increase the anchorage of PEG chains which makes surface hydrophilic. Experiments with 202 higher amount of PEGDA (0.4 M and 0.5 M) at 5 wt. \% BME, were tested. For 0.4 M PEGDA 
concentration, contact angle measured was $56^{\circ} \pm 4$. Photografting in these conditions was found 204 to be not repeatable; other COC-PEGDA plates presented a contact angle of $73^{\circ} \pm 3$. For $0.5 \mathrm{M}$ 205 PEGDA, the surface was hydrophilic with contact angle of $64^{\circ} \pm 4$. Nanoparticles on COC206 PEGDA plates for both photografting conditions were then observed by scanning electronic 207 microscopy (Figure 2).

208
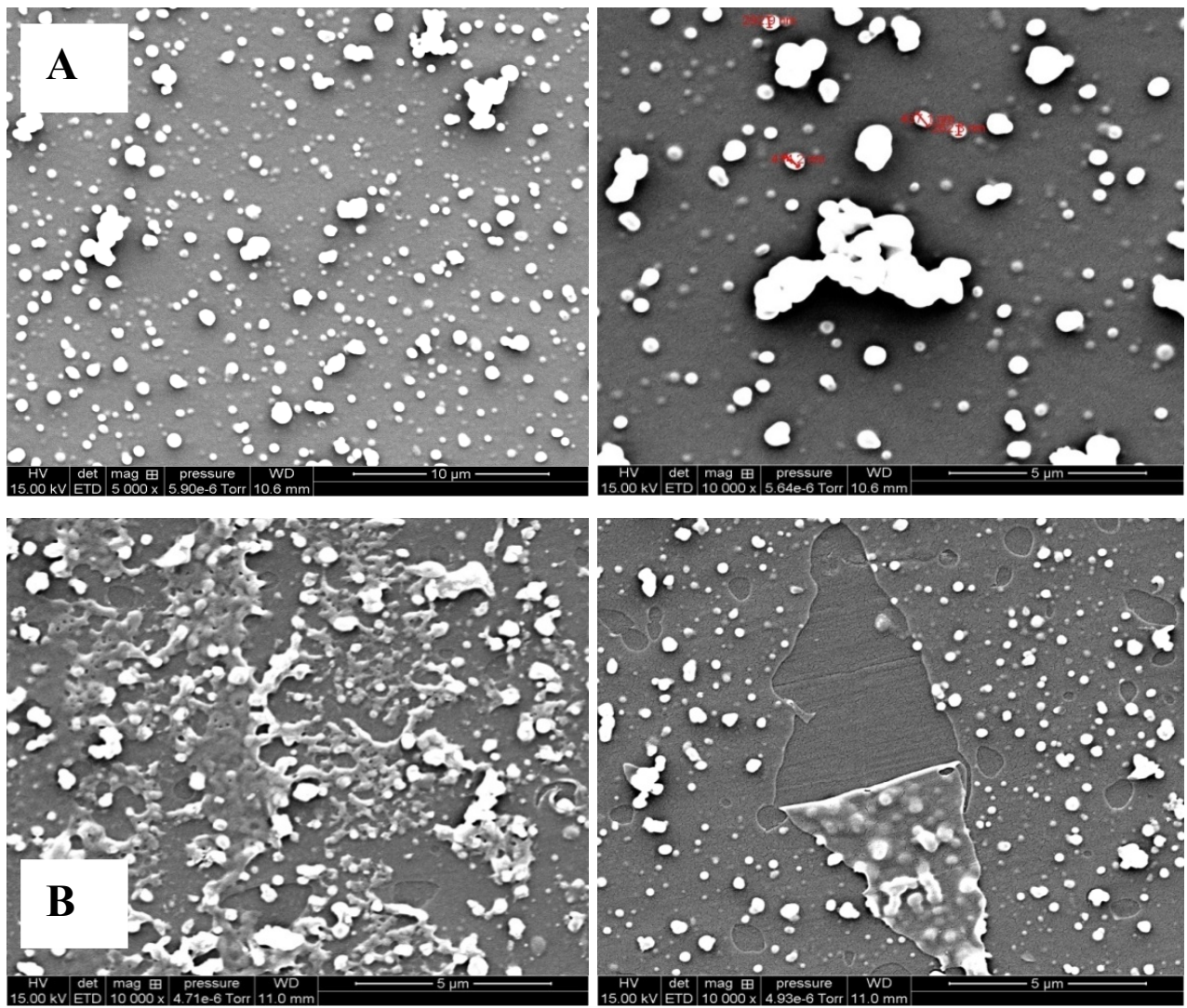

Figure 2 SEM Images A : 0.4 M PEGDA + $5 \%$ wt. BME in water/acetone 50/50 (v/v); $10 \mathrm{~min}, 45^{\circ} \mathrm{C}$, $2.7 \mathrm{~mW} / \mathrm{cm}^{2}$. MEB x 5000, x 10000. B : $0.5 \mathrm{M}$ PEGDA + $5 \%$ wt. BME in water/acetone 50/50 (v/v); $10 \mathrm{~min}, 45^{\circ} \mathrm{C}, 2.7 \mathrm{~mW} / \mathrm{cm}^{2}$. MEB x 10000. Miniemulsion photopolymerization: $30 \mathrm{~min}, 30^{\circ} \mathrm{C}$,

217 For 0.4 M PEGDA (Figure 2A) particles are merged and distorted. Acrylate layer, which is not 218 stable and peels off, was further observed for 0.5 M PEGDA (Figure 2B). To overcome these 219 problems, PEGDA concentration was fixed at $0.3 \mathrm{M}$ with 5 wt. \% of BME. For these conditions, 220 PEGDA-grafted COC plate contact angle was measured between $60^{\circ}$ and $65^{\circ}$ (Figure 1). The 
221 synthesis of nanoparticles on the modified COC plates using this protocol (0.3 M PEGDA and $2225 \%$ wt. BME) was characterized by SEM observations (Figure 3).

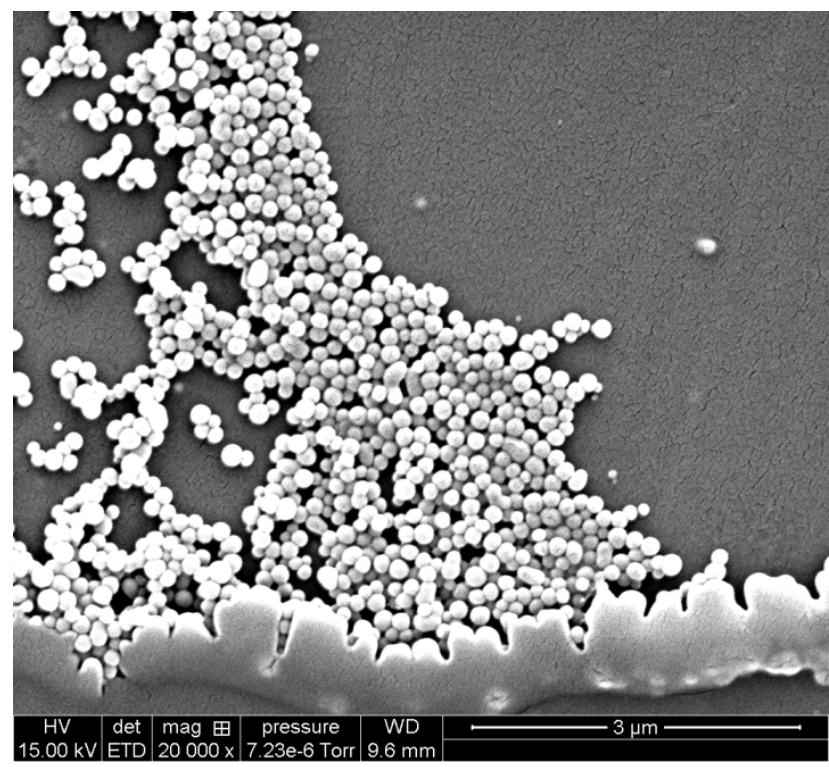

224 Figure 3 SEM image for nanoparticles on modified COC plate. PEGDA photografting : $0.3 \mathrm{M}$ 225 PEGDA + $5 \%$ wt. BME in water/acetone $50 / 50(\mathrm{v} / \mathrm{v}) ; 10 \mathrm{~min}, 45^{\circ} \mathrm{C}, 2.7 \mathrm{~mW} / \mathrm{cm}^{2}$. Miniemulsion 226 photopolymerization: $30 \mathrm{~min}, 30^{\circ} \mathrm{C}, 2.7 \mathrm{~mW} / \mathrm{cm}^{2}$. MEB x 20000 . Tension $15 \mathrm{kV}$.

228 Anchorage of spherical nanoparticles is unfortunately not sufficient and not homogeneous on COC

229 (Figure 3). It seems that PEG chains are not grafted on the surface because of the amount of BME 230 which might be insufficient to create active sites on COC by hydrogen abstraction. BME amount 231 impact PEGDA grafting, but furthermore number of active sites on COC surface. Therefore, 232 influence of BME was investigated by concentration.

\section{$233 \quad 3.3 \quad$ Influence of BME concentration}

234 Influence of BME amount on hydrophilicity COC surface was studied in percent in respect to 235 PEGDA weight to initiate reticulation of PEG chains and form a compact polymeric layer. 236 Furthermore, BME could act on COC surface by hydrogen abstraction, and therefore, it would be 237 interesting to analyse with another point of view the influence of the photoinitiator by controlling 238 BME concentration $(\mathrm{mM})$ in regards to the polymerization mixture. This concentration should be 239 optimized in order to promote a large number of active sites and enhance anchorage of 
240 nanoparticles. BME concentrations are mentioned in Table 3 , and the contour plot according to 241 BME and PEGDA concentration is represented in Figure 4.

243 Table 3 Experimental design expressed with BME concentration (mM)

\begin{tabular}{|l|l|l|l|l|l|}
\hline Experiments & $\begin{array}{l}\text { PEGDA } \\
\text { Concentration } \\
(\mathbf{M})\end{array}$ & $\begin{array}{l}\text { \% wt. } \\
\text { BME }\end{array}$ & $\begin{array}{l}\text { BME } \\
\text { concentration } \\
(\mathbf{m M})\end{array}$ & $\begin{array}{l}\text { Irradiation } \\
\text { time (min) }\end{array}$ & $\begin{array}{l}\text { Y1 : Contact } \\
\text { angle average } \\
\left({ }^{\circ}\right)\end{array}$ \\
\hline 1 & 0.10 & 1 & 1.14 & 10 & 84 \\
\hline 2 & 0.30 & 1 & 3.42 & 10 & 71 \\
\hline 3 & 0.10 & 5 & 5.70 & 10 & 76 \\
\hline 4 & 0.30 & 5 & 17.10 & 10 & 59 \\
\hline 5 & 0.10 & 1 & 1.14 & 20 & 84 \\
\hline 6 & 0.30 & 1 & 3.42 & 20 & 71 \\
\hline 7 & 0.10 & 5 & 5.70 & 20 & 73 \\
\hline 8 & 0.30 & 5 & 17.10 & 20 & 65 \\
\hline 9 & 0.10 & 3 & 3.42 & 15 & 79 \\
\hline 10 & 0.30 & 3 & 10.26 & 15 & 80 \\
\hline 11 & 0.20 & 1 & 2.28 & 15 & 84 \\
\hline 12 & 0.20 & 5 & 11.40 & 15 & 64 \\
\hline 13 & 0.20 & 3 & 6.84 & 10 & 83 \\
\hline 14 & 0.20 & 3 & 6.84 & 20 & 78 \\
\hline 15 & 0.20 & 3 & 6.84 & 15 & 86 \\
\hline 16 & 0.20 & 3 & 6.84 & 15 & 82 \\
\hline 17 & 0.20 & 3 & 6.84 & 15 & 75 \\
\hline & & & & \\
\hline
\end{tabular}




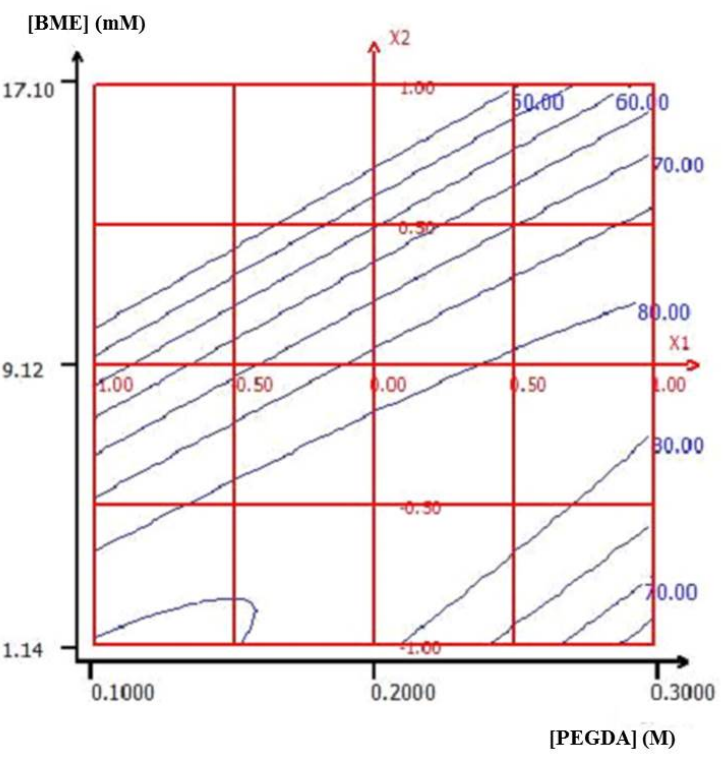

246 Figure 4 Contour plot of contact angle for $10 \mathrm{~min}$ of irradiation according to BME and PEGDA 247 concentration.

248 BME, by hydrogen abstraction, forms more active sites on the surface, which promote anchorage 249 of PEG chains. Contour plot of contact angle represented in Figure 4, indicated a hydrophilic 250 character for higher BME concentration. Thereby, the hypothesis is verified. For $17 \mathrm{mM} \mathrm{BME}$, 251 which is the maximum concentration that was tested, contact angle is between $50^{\circ}$ and $60^{\circ}$ for 252 various PEGDA concentrations $(0.1 \mathrm{M}-0.3 \mathrm{M})$. For these conditions, reproducibility of PEGDA 253 photografting was verified by three measures of contact angle (Figure 5).

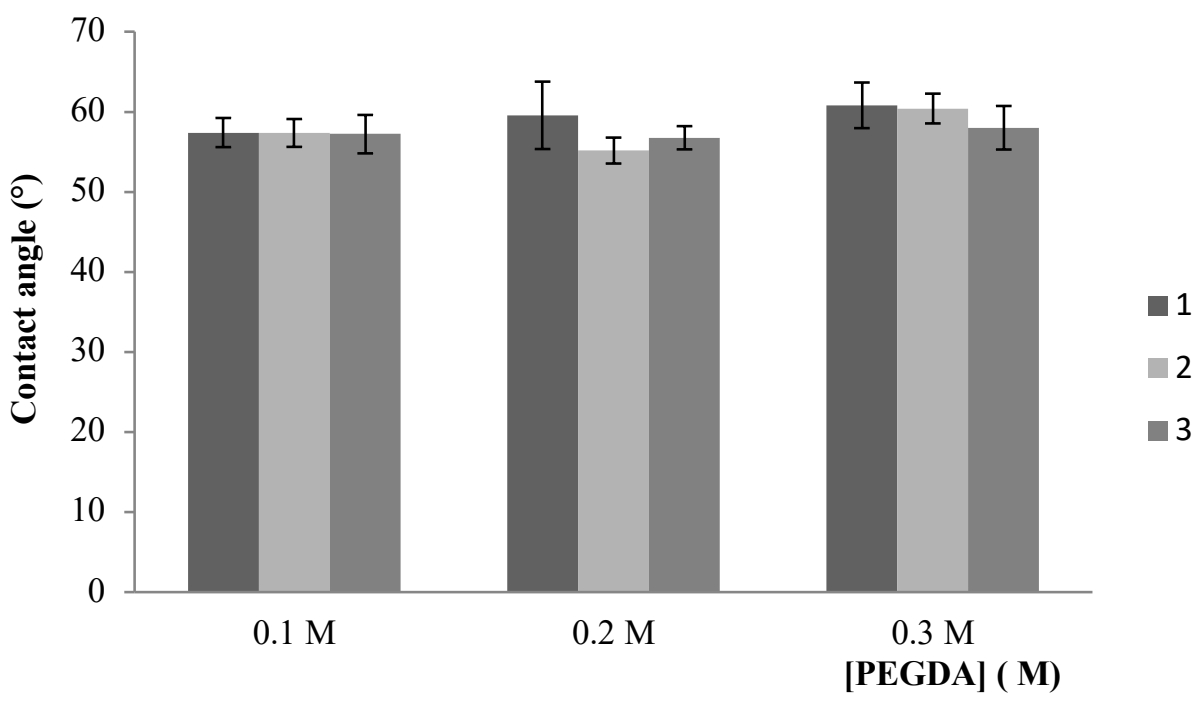


Figure 5 Reproducibility chart of PEGDA photografting. Contact angle $\left(^{\circ}\right)$ according to PEGDA

258 To follow the impact of BME and PEGDA concentration on the sphericity of particles,

259 UV-synthesis of acrylate particles on PEGDA-modified COC plates with $17 \mathrm{mM}$ BME and 260 PEGDA concentrations between $0.1 \mathrm{M}$ and $0.3 \mathrm{M}$ were performed. Figure 6 represent 261 morphologies of the resulting particles.

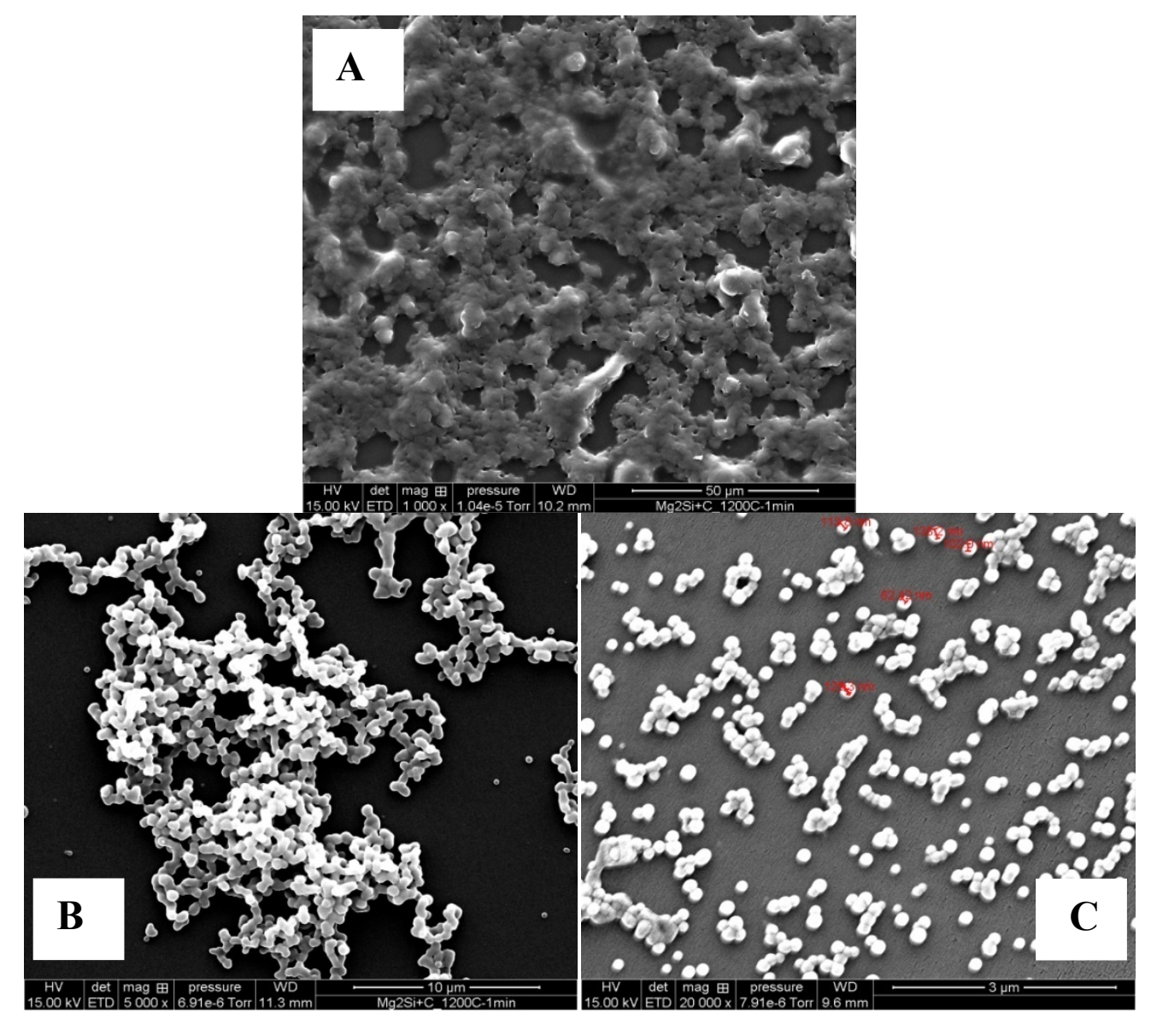

Figure 6 SEM Images of nanoparticles anchored on PEGDA-modified COC- surfaces. PEGDA photopolymerization with $17 \mathrm{mM} \mathrm{BME}, 10 \mathrm{~min}, 45^{\circ} \mathrm{C}, 2.7 \mathrm{~mW} / \mathrm{cm} . \mathbf{A}: 0.1 \mathrm{M}, \mathrm{MEB}$ X 1000. B : $0.2 \mathrm{M}$, 
MEB X 5000. C : $0.3 \mathrm{M}$ PEGDA concentration, respectively, MEB X 20000. Miniemulsion photopolymerization: $30 \mathrm{~min}, 30^{\circ} \mathrm{C}, 2.7 \mathrm{~mW} / \mathrm{cm}^{2}$. Tension $15 \mathrm{kV}$.

272 Figure 6A represent nanoparticles synthesis on modified COC with low concentration of PEGDA $273(0.1 \mathrm{M})$. Contact angle measured was between $55^{\circ}$ and $65^{\circ}$. SEM morphologies, showed a fusion 274 of particles on the surface. Low amount of PEGDA consumes a part of BME and the excess will 275 form free radicals by hydrogen abstraction from COC. The non-grafted COC surface by PEG 276 chains seems to destabilize miniemulsion due to his hydrophobic nature. For higher concentration 277 of PEGDA, nanoparticles become more spherical with diameter between $27880 \mathrm{~nm}$ and $140 \mathrm{~nm}$ for $0.3 \mathrm{M}$ PEGDA (Figure 6C). These results verified that low PEGDA 279 concentration, is not sufficient to consume BME and form spherical nanoparticles. Monodisperse 280 hexyl acrylate nanoparticles with diameter inferior to $200 \mathrm{~nm}$ are obtained for 0.3 M PEGDA at $28117 \mathrm{mM}$ BME, which is in accordance to the specifications.

282 Unfortunately, these irradiation conditions were not compatible with COC chips. A concentration 283 of 0.3 M PEGDA is considered too elevated for the surface modification to be implemented in 284 microchannels, as it oftenly leads to channel blockage. To overcome this problem, we extended 285 our study for PEGDA concentration field between $0.05 \mathrm{M}$ and $0.2 \mathrm{M}$.

\subsection{UV-Synthesis of nanoparticles on modified COC plates}

287 Anchorage of nanoparticles on COC-PEGDA surfaces depends on polymerization conditions. For 288 different synthesis on modified COC substrates, morphologies of nanoparticles were followed by SEM images. PEGDA photografting was explored for various PEGDA concentrations: $0.05 \mathrm{M}$, $2900.1 \mathrm{M}$ and $0.2 \mathrm{M}$ with BME concentrations reaching $17 \mathrm{mM}, 30 \mathrm{mM}$ and $50 \mathrm{mM}$ (Figure 7). BME 291 concentration impacts the number of PEGDA chains grafted. At higher concentration an increase 292 of the number of PEGDA chains can be observed. Otherwise, an excess of non-reacted BME can 293 interfere with COC surface.

294 On the first hand, the diagram is interpreted in a horizontal manner. For a fixed value of BME 295 concentration, no particles were observed at 0.05 $\mathrm{M}$ and 0.1 M PEGDA. Particles are fusion and 296 leads to an acrylate monolayer. PEGDA concentrations seem insufficient to consume BME even 297 at low concentration of $17 \mathrm{mM}$. Therefore, the miniemulsion was not stable in contact with the 298 surface, as previously observed. At 0.2 M PEGDA, SEM images showed spherical particles 299 anchored on COC surface. On the other hand, a vertical analysis of Figure 10 showed that more 
300 particles distortion and acrylate layers happened for $0.05 \mathrm{M}$ and $0.1 \mathrm{M}$ PEGDA at higher 301 concentrations of BME. This might be due to the excess of BME non-reacted. For PEGDA 302 concentration higher than $0.2 \mathrm{M}$ with higher concentration of BME more active sites were formed. 303 Thus, the number of spherical particles on the surface was enhanced.

304 In conclusion, PEGDA and BME amounts not only impact the hydrophilicity nature of COC but 305 also the sphericity of nanoparticles anchored. The increase of BME concentration leads to an 306 increase of active sites occupied then by PEGDA at higher concentrations. Therefore an increase 307 of number of spherical nanoparticles on the surface is observed. 0.2 M PEGDA at $30 \mathrm{mM} \mathrm{BME}$ 308 respond to the specification. 


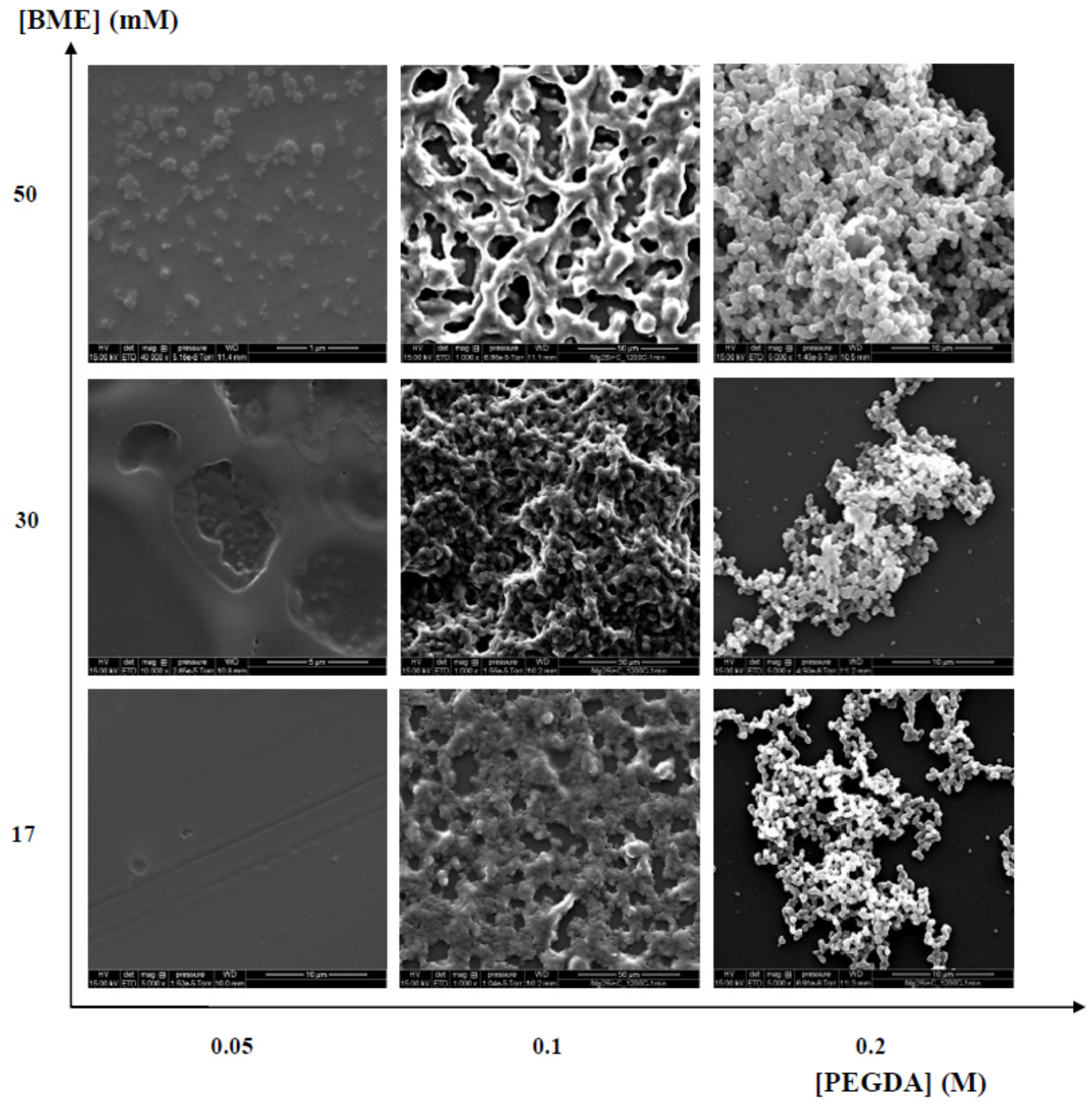

310 Figure 7 SEM Images of nanoparticles anchored on modified COC surfaces by different PEGDA and 311 BME concentrations. Photopolymerization: $10 \mathrm{~min}, 45^{\circ} \mathrm{C}, 2.7 \mathrm{~mW} / \mathrm{cm}$. Miniemulsion 312 photopolymerization: $30 \mathrm{~min}, 30^{\circ} \mathrm{C}, 2.7 \mathrm{~mW} / \mathrm{cm}^{2}$. Tension $15 \mathrm{kV}$. 


\section{Conclusion}

317 The anchorage of hexyl acrylate nanoparticles on COC surface requires a surface modification

318 from hydrophobic to hydrophilic nature. This study studied the optimization of PEGDA

319 photografting by using response surface methodology as regard to PEGDA and BME amounts and

320 irradiation time. A large experimental field has been explored using water contact angle

321 measurement which indicates the hydrophobic/hydrophilic nature of the substrate. COC surface

322 has been considered sufficiently hydrophilic for a contact angle inferior to $65^{\circ}$. The hydrophilic

323 PEGDA-modified COC surface promotes anchorage of nanoparticles, as observed by SEM

324 images. Both PEGDA and BME concentrations used during the first surface modification step

325 impact the anchorage of nanoparticules that occurs during in-situ photopolymerization as well as

326 the morphology of the resulting particles. A compromise between PEGDA and BME amount

327 should be made to maintain spherical particles sufficiently anchored on COC plates and 328 microchips. Synthesis of nanoparticles on modified COC plates grafted with PEGDA was

329 achieved. An optimization of polymerization conditions in COC microchips should be done to 330 avoid plugging channels and to develop a novel stationary phase which could be used in 331 electrochromatography.

\section{Acknowledgements}

333 The authors acknowledge the financial support by French National Research Agency (ANR) 334 through Nanochrom project (11-JS09-017-01). 


\section{References}

344 1. Knox, J.H. and M. Saleem, Kinetic Conditions for Optimum Speed and Resolution in

345 Column Chromatography. Journal of Chromatographic Science, 1969. 7(10): p. 614-622.

346 2. Knox, J.H., Practical Aspects of LC Theory. Journal of Chromatographic Science, 1977. 15(9): p. 352-364.

3. Desmet, G., D. Clicq, and P. Gzil, Geometry-Independent Plate Height Representation Methods for the Direct Comparison of the Kinetic Performance of LC Supports with a Different Size or Morphology. Analytical Chemistry, 2005. 77(13): p. 4058-4070.

4. Nguyen, D.T.T., et al., Chromatographic behaviour and comparison of column packed with sub-2 $\mu$ m stationary phases in liquid chromatography. Journal of Chromatography A, 2006. 1128(1-2): p. 105-113.

5. Nguyen, D.T.T., et al., Fast analysis in liquid chromatography using small particle size and high pressure. Journal of Separation Science, 2006. 29(12): p. 1836-1848.

6. Kundu, P., et al., Stability of oil-in-water macro-emulsion with anionic surfactant: Effect of electrolytes and temperature. Chemical Engineering Science, 2013. 102(0): p. 176185.

7. Chemtob, A., et al., Photoinduced miniemulsion polymerization. Colloid and Polymer Science, 2010. 288(5): p. 579-587.

8. Hoijemberg, P.A., A. Chemtob, and C. Croutxé-Barghorn, Two Routes Towards Photoinitiator-Free Photopolymerization in Miniemulsion: Acrylate Self-Initiation and Photoactive Surfactant. Macromolecular Chemistry and Physics, 2011. 212(22): p. $2417-$ 2422.

9. Saadé, J., et al., Response surface optimization of miniemulsion: application to UV synthesis of hexyl acrylate nanoparticles. Colloid and Polymer Science, 2015. 294(1): p. 27-36.

10. Yang, W. and B. Rånby, Radical Living Graft Polymerization on the Surface of Polymeric Materials. Macromolecules, 1996. 29(9): p. 3308-3310.

11. Ma, Y., L. Liu, and W. Yang, Photo-induced living/controlled surface radical grafting polymerization and its application in fabricating 3-D micro-architectures on the surface of flat/particulate organic substrates. Polymer, 2011. 52(19): p. 4159-4173.

12. Ma, H., R.H. Davis, and C.N. Bowman, A Novel Sequential Photoinduced Living Graft Polymerization. Macromolecules, 1999. 33(2): p. 331-335.

13. Zhao, C., Z. Zhang, and W. Yang, A remote photochemical reaction for surface modification of polymeric substrate. Journal of Polymer Science Part A: Polymer Chemistry, 2012. 50(18): p. 3698-3702.

14. Schneider, M.H., Y. Tran, and P. Tabeling, Benzophenone Absorption and Diffusion in Poly(dimethylsiloxane) and Its Role in Graft Photo-polymerization for Surface Modification. Langmuir, 2011. 27(3): p. 1232-1240.

15. Ladner, Y., et al., New "one-step" method for the simultaneous synthesis and anchoring of organic monolith inside COC microchip channels. Lab on a Chip, 2012. 12(9): p. 1680-1685.

16. Wang, Y. and W. Yang, MMA/DVB Emulsion Surface Graft Polymerization Initiated by UV Light. Langmuir, 2004. 20(15): p. 6225-6231. 
17. Wang, Y., et al., Directly Fabricating Monolayer Nanoparticles on a Polymer Surface by UV-Induced MMA/DVB Microemulsion Graft Polymerization. Macromolecular Rapid Communications, 2005. 26(2): p. 87-92.

18. Gustafsson, O., K.B. Mogensen, and J.P. Kutter, Underivatized cyclic olefin copolymer as substrate material and stationary phase for capillary and microchip electrochromatography. ELECTROPHORESIS, 2008. 29(15): p. 3145-3152.

19. Rohr, T., et al., Surface Functionalization of Thermoplastic Polymers for the Fabrication of Microfluidic Devices by Photoinitiated Grafting. Advanced Functional Materials, 2003. 13(4): p. 264-270.

20. Kumlangdudsana, P., S.T. Dubas, and a.L. Dubas, Surface Modification of Microfluidic Devices. Journal of Metals, Materials and Minerals., 2007.17 (2): p. 67-74.

21. Roy, S., et al., Surface analysis, hydrophilic enhancement, ageing behavior and flow in plasma modified cyclic olefin copolymer (COC)-based microfluidic devices. Sensors and Actuators B: Chemical, 2010. 150(2): p. 537-549.

22. Roy, S. and C.Y. Yue, Surface Modification of COC Microfluidic Devices: A Comparative Study of Nitrogen Plasma Treatment and its Advantages Over Argon and Oxygen Plasma Treatments. Plasma Processes and Polymers, 2011. 8(5): p. 432-443.

23. Tsao, C.W., et al., Low temperature bonding of PMMA and COC microfluidic substrates using UV/ozone surface treatment. Lab on a Chip, 2007. 7(4): p. 499-505.

24. Zhang, J., C. Das, and Z.H. Fan, Dynamic coating for protein separation in cyclic olefin copolymer microfluidic devices. Microfluidics and Nanofluidics, 2008. 5(3): p. 327-335.

25. Brisset, F., et al., Surface functionalization of cyclic olefin copolymer with aryldiazonium salts: A covalent grafting method. Applied Surface Science, 2015. 329(0): p. 337-346.

26. Li, C., et al., Isoelectric focusing in cyclic olefin copolymer microfluidic channels coated by polyacrylamide using a UV photografting method. Electrophoresis, 2005. 26(9): p. 1800-6.

27. Stachowiak, T.B., et al., Hydrophilic surface modification of cyclic olefin copolymer microfluidic chips using sequential photografting. J Sep Sci, 2007. 30(7): p. 1088-93.

28. Hu, S., et al., Surface-Directed, Graft Polymerization within Microfluidic Channels. Analytical Chemistry, 2004. 76(7): p. 1865-1870.

29. Burke, J.M. and E. Smela, A novel surface modification technique for forming porous polymer monoliths in poly(dimethylsiloxane), in Biomicrofluidics. 2012: United States. p. 16506-1650610.

30. Almutairi, Z., C.L. Ren, and L. Simon, Evaluation of polydimethylsiloxane (PDMS) surface modification approaches for microfluidic applications. Colloids and Surfaces A: Physicochemical and Engineering Aspects, 2012. 415(0): p. 406-412.

31. Stachowiak, T.B., F. Svec, and J.M.J. Fréchet, Patternable Protein Resistant Surfaces for Multifunctional Microfluidic Devices via Surface Hydrophilization of Porous Polymer Monoliths Using Photografting. Chemistry of Materials, 2006. 18(25): p. 5950-5957.

32. Kholdi, O.E., et al., Modification of adhesive properties of a polyethylene film by photografting Journal of Applied Polymer Science Volume 92, Issue 5. Journal of Applied Polymer Science, 2004. 92(5): p. 2803-2811.

33. Wang, H. and H.R. Brown, Ultraviolet grafting of methacrylic acid and acrylic acid on high-density polyethylene in different solvents and the wettability of grafted high-density polyethylene. I. Grafting. Journal of Polymer Science Part A: Polymer Chemistry, 2004. 42(2): p. 253-262. 
34. Li, G., et al., Surface photografting initiated by benzophenone in water and mixed solvents containing water and ethanol. Journal of Applied Polymer Science, 2012. 123(4): p. 1951-1959.

35. Yang, W. and B. Rånby, Bulk surface photografting process and its applications. II. Principal factors affecting surface photografting. Journal of Applied Polymer Science, 1996. 62(3): p. 545-555.

36. Decker, C. and K. Zahouily, Surface modification of polyolefins by photografting of acrylic monomers. Macromolecular Symposia, 1998. 129(1): p. 99-108.

37. Wang, Y., et al., Facile Surface Superhydrophilic Modification: NVP/MBA Inverse Microemulsion Surface-Grafting Polymerization Initiated by UV Light. Macromolecular Rapid Communications, 2005. 26(22): p. 1788-1793.

38. He, D. and M. Ulbricht, Surface-selective photo-grafting on porous polymer membranes via a synergist immobilization method. Journal of Materials Chemistry, 2006. 16(19): p. 1860-1868.

39. Balart, J., et al., Surface modification of polypropylene substrates by UV photografting of methyl methacrylate (MMA) for improved surface wettability. Journal of Materials Science, 2012. 47(5): p. 2375-2383.

40. Ma, H., R.H. Davis, and C.N. Bowman, Principal factors affecting sequential photoinduced graft polymerization. Polymer, 2001. 42(20): p. 8333-8338.

41. Feng, Y., et al., Grafting of poly(ethylene glycol) monoacrylates on polycarbonateurethane by UV initiated polymerization for improving hemocompatibility. Journal of Materials Science: Materials in Medicine, 2013. 24(1): p. 61-70.

42. Stachowiak, T.B., et al., Fabrication of porous polymer monoliths covalently attached to the walls of channels in plastic microdevices. Electrophoresis, 2003. 24(21): p. 36893693.

43. Jena, R.K., C.Y. Yue, and L. Anand, Improvement of thermal bond strength and surface properties of Cyclic Olefin Copolymer (COC) based microfluidic device using the photografting technique. Sensors and Actuators B: Chemical, 2011. 157(2): p. 518-526.

44. Roy, S., et al., Low-temperature (below Tg) thermal bonding of COC microfluidic devices using UV photografted HEMA-modified substrates: high strength, stable hydrophilic, biocompatible surfaces. Journal of Materials Chemistry, 2011. 21(38): p. 15031-15040.

45. Roy, S., et al., Fabrication of smart COC chips: Advantages of N-vinylpyrrolidone (NVP) monomer over other hydrophilic monomers. Sensors and Actuators B: Chemical, 2013. 178(0): p. 86-95.

46. Du, G., et al., In-channel tuning of hydrophilicity and surface charge of cyclic olefin copolymer microchips by UV-induced graft polymerization and its application in lab-ona-chip devices. Chemical Engineering Journal, 2012. 195-196(0): p. 132-139.

47. Peng, X., et al., Charge Tunable Zwitterionic Polyampholyte Layers Formed in Cyclic Olefin Copolymer Microchannels through Photochemical Graft Polymerization. ACS Applied Materials \& Interfaces, 2013. 5(3): p. 1017-1023. 